\title{
Batch Electrocoagulation Treatment of Peat Water in Sarawak with Galvanized Iron Electrodes
}

\author{
Nazzeri Abdul Rahman ${ }^{1, a^{*}}$, Nur Afifah Tomiran ${ }^{1, b}$ and Aiman Hakim Hashim ${ }^{1, c}$ \\ ${ }^{1}$ Department of Chemical Engineering and Energy Sustainability, Faculty of Engineering, Universiti \\ Malaysia Sarawak, 94300 Kota Samarahan, Sarawak, Malaysia \\ aarnazeri@unimas.my, bnurafifahtomiran@gmail.com, caiman512@ymail.com
}

Keywords: Peat water, Electrocoagulation, Galvanized iron

\begin{abstract}
Peat water is an abundant water resource in Sarawak where some of the coastal areas in Sarawak still utilize peat water for domestic usage. Peat water contains natural organic matters especially humic substances which include humic acids. Humic acids contribute to the brown color of peat water and can cause diseases such as stomach cancer, blackfoot disease and etc. if consumed by human. Electrocoagulation is an alternative to conventional water treatment methods which have the advantages of being environmental friendly, minimal sludge production and no addition of chemical substances. The aims of this study are to fabricate a desktop scale electrocoagulation system with galvanised iron electrodes and to investigate the effects of the operating parameters such as interelectrode distance, applied current density, number of electrodes, and treatment time on peat water in the system. The performance of batch electrocoagulation system in term of their removal efficiency of several parameters such as total organic carbon (TOC), chemical oxygen demand (COD), color and turbidity are evaluated. Through experimental tests conducted, this system successfully removes $98.44 \%$ of COD, $92.02 \%$ of TOC, $97.92 \%$ of turbidity and $99.91 \%$ of color by using galvanized iron as an electrode at current density of $25 \mathrm{~A} / \mathrm{m}^{2}$ in 30 minutes with 10 galvanized iron electrodes. Despite the fact that there is a small amount of iron ions and zinc ions remained in the treated peat water which are $0.001 \mathrm{mg} / 1$ and $0.0442 \mathrm{mg} / 1$ respectively, these concentrations are far below the standard limits imposed by Malaysia Ministry of Health $(\mathrm{MOH})$. Generally, all the parameters studied meet the standard limit imposed by $\mathrm{MOH}$ except for total organic carbon. This is particularly due to the improper filtration system adopted in this study. The total operating costs for $25 \mathrm{~A} / \mathrm{m}^{2}$ in 30 minutes treatment time of 10 electrode plates is RM 8.75 per $^{3}$. Overall, the study have successfully designed a batch electrocoagulation system to treat peat water by using galvanized iron for domestic usage.
\end{abstract}

\section{Introduction}

Sarawak, the biggest state in Malaysia, has the largest reserve of peatland in Malaysia. According to Sa'don et al. [1], almost 13\% of the Sarawak State's total area is covered by peat. Among the typical peat characteristics, as found in Sarawak, are the presence of organics matter in significant quantities of at least $30 \%$, particularly complex aromatic compounds known as humic substances [2]. Humic substances cause a yellowish to brown color, odorous, acidity taste in peat water which are produced from animal decay and plant residues by means of microorganism activities. Due to its abundance, especially in coastal area of Sarawak, peat water has the potential to be the raw water source for domestic water supply especially for rural areas that are not connected to municipal water supply.

Due to its simple operation, electrocoagulation is an alternative method to chemical coagulation. This process combines the conventional coagulation and electrochemistry to treat peat water problem that involves electrochemical of metal dissolution and water reduction, oxidation or reduction, chemical mechanisms such as hydroxide precipitation and redox reaction in water and physical mechanism as physical adsorption, coagulation, and flotation of floc. Moreno et al. [3] define electrocoagulation as an electrochemical process used to treat wastewater where an electrical charge from dc voltage is applied to wastewater to form flocs. The typical electrode used in electrocoagulation are iron or aluminum due to the metals good electrocoagulation performance and lower cost for the removal of organic matters and nutrients existing in wastewater [4]. 